\title{
Privacidade intradomiciliar: um estudo sobre as necessidades de ampliações em residências*
}

\author{
Gustavo Henrique Naves Givisiez ${ }^{* *}$ \\ Elzira Lúcia de Oliveira**
}

Uma habitação adequada deve possuir um espaço protegido de intempéries e apresentar condições favoráveis de salubridade, privacidade e segurança. Este artigo aborda a privacidade interna das moradias e sua capacidade em abrigar famílias de composições variadas com critérios mínimos de conforto. Parte das ações governamentais direcionadas à população de baixa renda deve envolver, além da construção de casas, a requalificação de imóveis e a prestação de assistência técnica. 0 presente artigo objetiva propor um critério para avaliar a privacidade interna das moradias, por meio de um indicador de necessidades de ampliações, estimado a partir de um número necessário de cômodos de apoio, dormitórios e banheiros, com base na idade, sexo e status conjugal dos moradores. Os critérios propostos ainda qualificam o indicador em sete niveis de necessidade, que variam entre a ampliação de apenas um cômodo, no nível mais brando, até a necessidade de construção de banheiro e, pelo menos, mais quatro cômodos, em seu nível mais avançado. Entende-se que o indicador proposto pode ser útil na concepção de políticas públicas voltadas à reforma e ampliação de residências. Os resultados indicam que $46 \%$ dos domicílios brasileiros, em 2008, demandavam reformas ou ampliações, mas a qualificação dessa demanda indica que as políticas públicas destinadas às reformas poderiam ser focalizadas, por exemplo, em níveis mais avançados de inadequação que totalizariam, aproximadamente, 16\% dos domicílios no Brasil. A maior proporção de domicílios adequados é verificada na Região Sul (67\%) e a menor na Região Norte, onde apenas 37\% dos desses são adequados.

Palavras-chave: Demografia aplicada. Habitação. Déficit habitacional. Densidade domiciliar. Coabitação.

\footnotetext{
* Este artigo é baseado em projetos de pesquisa apoiados pela Fundação de Amparo a Pesquisa do Rio de Janeiro Carlos Chagas Filho (Faperj) e pelo Conselho Nacional de Desenvolvimento Científico e Tecnológico (CNPq).

** Arquiteto, doutor em Demografia pelo Cedeplar/UFMG, professor adjunto, Departamento de Geografia de Campos, Universidade Federal Fluminense (ghnaves@globo.com).

*** Economista, doutora em Demografia pelo Cedeplar/UFMG, professora adjunta, Departamento de Geografia de Campos, Universidade Federal Fluminense (elziralucia@globo.com).
} 


\section{Introdução}

É inquestionável que uma habitação adequada deve ter espaço protegido das intempéries, com condições favoráveis de salubridade, privacidade e segurança. É consenso também que o crescimento acelerado das cidades produziu espaços urbanos onde se observam ambientes de pobreza, degradação ambiental, carência de serviços urbanos essenciais e residências insalubres. Esse processo reflete, entre outros aspectos, a dificuldade de acesso ao solo urbano e também o fato de ser a moradia o bem mais caro entre as necessidades básicas e essenciais de uma família.

Mas a habitação envolve ainda dimensões subjetivas e diferenças culturais que podem ser muito diferentes entre países ou classes sociais. No Brasil, a demanda por residências, para as classes média e alta, é dependente das etapas de ciclo de vida, enquanto, para as classes menos privilegiadas, está relacionada à privação total desse bem ou à adequação da moradia existente a condições mínimas de habitabilidade. Para quantificar essas questões, várias metodologias foram desenvolvidas para a estimativa de necessidades habitacionais, o que se convencionou a chamar de déficit habitacional. Vale ressaltar que as metodologias são distintas e se prestam a diferentes aplicações, dependendo do tipo de utilização e da base de dados disponível (VASCONCELOS; CÂNDIDO Jr., 1996; GENEVOIS; COSTA, 2001; FJP, 2001; INDEC, 2003, entre outros).

Contudo, a concepção estática dos critérios de estimativa das necessidades habitacionais pode tornar essas metodologias obsoletas. À medida que a situação econômica de um país ou região melhora, características novas e imprevisíveis ganham importância, e o que se observa na estimativa das necessidades habitacionais é a progressiva transição de uma fase quantitativa para uma fase qualitativa e de estimação mais complexa (GIVISIEZ; RIOS-NETO; SAWYER, 2006). Nesse sentido, entende-se que as metodologias para a categorização de domicílios em adequados ou deficitários devem ser continuamente revisadas para adequá-las às demandas da sociedade. Nesse contexto, um ponto relevante refere-se ao tamanho das residências e à capacidade de abrigar adequadamente famílias de composições variadas com critérios mínimos de privacidade e conforto e, por isso, além da construção de casas, as ações governamentais, direcionadas à população de baixa renda, devem envolver reformas, ampliações, requalificação de imóveis e prestação de assistência técnica. Assim, o desenvolvimento de critérios e técnicas que estimem o estoque de residências em que essas ações governamentais devem ser priorizadas é uma lacuna que merece consideração.

A proposta deste artigo é aprofundar a discussão sobre a privacidade das moradias, estimada, no caso do déficit habitacional adotado pelo governo brasileiro (FJP, 2006), por meio da densidade excessiva de moradores por dormitório. É fato que a densidade excessiva das moradias identifica satisfatoriamente moradias pequenas com famílias grandes, entretanto, esse critério não avalia o tamanho físico das moradias e também ignora o sexo e a idade dos moradores. Suspeita-se de que uma parte do estoque de residências estaria com tamanho inadequado para abrigar diferentes arranjos domiciliares e que essa dimensão não é captada 
pelo indicador de déficit adotado pela política habitacional brasileira (FJP, 2006). O trabalho ora apresentado inspira-se em original proposto por Ricci (1973) que, baseando-se em índices regionais de adensamento domiciliar, observa que é legítimo questionar se os indicadores de superpopulação dos domicílios correspondem a iguais graus de inadequação domiciliar.

Assim, usando como fonte as informações da Pesquisa Nacional por Amostra de Domicílios - PNAD, será sugerido um indicador de necessidades de ampliações que parte de uma estimativa do número necessário de salas, cozinhas, dormitórios e banheiros para acomodar os distintos domicílios, baseando-se na idade, status conjugal e sexo dos membros. O total de cômodos necessários é contraposto com o total de cômodos existentes para estimar a demanda potencial por ampliações. O material usado na construção de paredes e tetos também é acrescentado ao indicador, de forma a qualificar se a necessidade é apenas de ampliações (construção de cômodos) ou também de reformas (substituição de paredes e coberturas). Ainda que exista uma correlação entre o adensamento excessivo e o indicador proposto neste trabalho, entende-se que a qualificação da adequação das famílias às suas moradias tem aplicabilidade direta nas políticas de habitação do país, uma vez que analisa de forma mais aprofundada a questão da privacidade, sendo esse um indicador útil no desenho de políticas públicas voltadas à reforma e ampliação de residências, assim como para estimativa de demandas para prestação de serviços públicos de assistência técnica em engenharia e arquitetura.

\section{Antecedentes}

O estudo científico da habitação humana, bem como suas relações com as diversas áreas do conhecimento, sugere que a abordagem do tema deve ser sempre multidisciplinar. Belo (2010), em um breve estudo filosófico sobre os temas "habitar" e "habitação", aborda as famílias, os núcleos sociais mais próximos aos indivíduos, e as suas normas:

Ora, é óbvio que não se habita na rua: uma sociedade não é, como se crê muitas vezes, um conjunto de indivíduos, a população dum território, mas a rede organizada de unidades sociais de habitação, o sistema complexo dos usos que nessa terra se transmitem de geração em geração. "Terra" aliás é melhor do que "território", porque tem em conta a agricultura e o gado, tem em conta que ao nível biológico também vimos de inúmeras doações, e justamente a refeição - festas são almoços - é um dos momentos fortes das unidades sociais de habitação a que chamamos família, em que os seus vários membros se encontram como unidade social que se apropria do "comum". Uma família é uma unidade social em propriedade privada: é o "comum" que é privado duma potência sua para que a unidade social - sistemas regrados de usos - se possa reproduzir. (BELO, 2010, p. 22).

Sob a ótica da construção física, a bibliografia nacional apresenta estudos sobre as técnicas das construções de moradias, referenciando, entre outros, a tecnologia aplicada nas obras (PICANÇO; GHAVAMI, 2008), os projetos (PANDOLFO et al., 2007), a eficiência térmica (FRANSOZO; SOUZA; FREITAS, 2005; KRÜGER; LAROCA, 2009) e a logística dos materiais (AGUIRRE; HENNIES, 2010). 
De um ponto de vista próximo às Ciências Sociais Aplicadas, referências datadas do fim do século XIX e citadas em estudos contemporâneos, frequentemente, associam as características da moradia à saúde dos seus moradores (GONÇALVEZ; SIMÕES; FREIRE, 2010). Sob essa ótica, a literatura nacional apresenta uma quantidade expressiva de trabalhos sobre a qualidade das habitações e a saúde pública (VALADARES, 2000; COHEN et al., 2004; AZEREDO et al., 2007), por vezes associando-as a doenças como a tuberculose (GONÇALVES, 2000), dengue (TAUIL, 2011), doença de Chagas (DIAS, 2011), entre outros exemplos. Destacam-se, ainda, os trabalhos que avaliam e discutem as políticas habitacionais nacionais, a exemplo de Maricato (2011), Barreto, Paula e Gontijo (2010), Morais, Cruz e Oliveira (2003) e Santos (1999).

A demografia, por sua vez, tem expressiva aderência ao tema “habitação”, em especial na abordagem da composição das famílias e na descrição das características dos domicílios. Nas palavras de Oliveira, Vieira e Barros (2010, p. 3):

Os domicílios encontram-se profundamente marcados pela maneira como as famílias são estruturadas e pelas estratégias que elas utilizam para atender às necessidades mínimas de moradia e sobrevivência.

Mulder e Lauster (2010), em editorial para edição especial sobre housing and family, da revista acadêmica Housing Studies, descrevem diversas associações entre os denominados families events e os housing events. Nesse contexto, podem ser citados os trabalhos de: Mulder e Billari (2010), que apresentam avaliações sobre as práticas de homeownership e a baixa fecundidade de países ocidentais; de Ström (2010), que explora as características das residências (propriedade, tamanho e tipo) e o evento do primeiro filho; de Feijten e Van Ham (2010), abordando divórcios e separações e eventos associados à habitação; e de South, Pais e Crowder (2011), que analisam a migração de grupos sociais distintos, dentro de regiões metropolitanas estadunidenses.

Outro ponto, que reforça a importância da demografia nos estudos sobre habitação, refere-se aos próprios censos demográficos e pesquisas domiciliares que, embora não exclusivamente desenhados para estimar as características das habitações, são úteis na quantificação do total de moradias inadequadas e, nesse sentido, têm sido continuamente aperfeiçoados na forma de investigação sobre os arranjos familiares e as características dos domicílios.

A demografia também é, principalmente na bibliografia internacional, referenciada quando da elaboração de estimativas de demanda por habitações e, dessa forma, grande parte da dinâmica de formação e dissolução de domicílios associa-se a fenômenos que compõem o universo de estudo da demografia. Nesse sentido, as principais metodologias de projeção de demanda por habitação fazem uso intensivo de referências e fontes demográficas, como, por exemplo, as projeções por meio das taxas de chefia de domicílio (UNITED NATIONS, 1973; KING, 1999; OLIVEIRA; GIVISIEZ; RIOS-NETO, 2009), ou os métodos baseados em 
estimativas das taxas de transições entres os “eventos familiares” (Yl et al., 2003; O’NEILL; JIANG, 2007; FIORAVANTE, 2009).

As abordagens das necessidades habitacionais, por fim, são, no contexto acadêmico brasileiro, as mais comumente referenciadas. As dimensionalidades exploradas nessas estimativas dependem de conceitos subjetivos e da aplicabilidade pretendida pela pesquisa, mas, grosso modo, o que se convencionou a denominar de déficit e carências habitacionais é baseado em normas sociais de inadequação, adensamento e carência de infraestrutura. 0 déficit habitacional é, nesse caso, operacionalizado por meio de um número que representa as necessidades habitacionais em um momento e que é comparado com o estoque de moradias em condições de atender, satisfatoriamente, à população.

De forma simplificada, para a estimativa de qualquer indicador de necessidades habitacionais, deve ser elencado um conjunto de características que conferem o caráter de moradias habitáveis às construções, devendo apresentar requisitos mínimos de construção e conservação (RODRIGUEZ, 2000). Em termos mais específicos, uma moradia adequada deve: ser capaz de proteger seus moradores do ambiente externo; dispor de um espaço de privacidade; e oferecer um ambiente sadio. Outras questões ainda são frequentemente acrescentadas a essas estimativas, como, por exemplo, a cobertura legal para ocupar uma moradia, seja pela posse, contrato de locação ou valores aceitáveis de aluguel (FJP; BRASIL, 2009; INDEC, 2001), a vulnerabilidade econômica do domicílio (INDEC, 2001) e a vulnerabilidade social das famílias (INDEC, 2001).

No caso da operacionalização do critério sobre proteção às intempéries e do ambiente externo, as variáveis mais frequentemente utilizadas são os materiais de construção de pisos, paredes e tetos. Entretanto, o tipo de material depende de critérios culturais, econômicos e sociais de cada região. Em locais sujeitos a desastres naturais, tais como enchentes, inundações, deslizamentos e terremotos, pode ser necessário o levantamento de outras variáveis. Em locais onde a segurança pública seja relevante, a exemplo de grandes cidades, critérios associados a segurança pública, iluminação pública, muros e arruamento podem também ser importantes. No caso do indicador de necessidades habitacionais, elaborado pela Fundação João Pinheiro - FJP (FJP; BRASIL, 2009), ${ }^{1}$ a estimativa dessa dimensão aborda a proporção de moradias com tetos e paredes construídos com materiais não duráveis.

O critério referente à salubridade da residência, por sua vez, é, geralmente, estimado com base em variáveis sobre a disponibilidade e qualidade de serviços públicos, como água, esgoto e energia elétrica. Estudos específicos podem ser desenvolvidos para abordar outros aspectos de salubridade, como ventilação e iluminação de cômodos, mas, obviamente, os critérios dependerão também de questões culturais, ambientais e sociais. No Brasil, o maior problema relaciona-se a salubridade, ocupação desordenada do solo urbano e ocupação

\footnotetext{
${ }^{1} 0$ desenho do déficit habitacional brasileiro (FJP, 2009) foi concebido para subsidiar o desenho de políticas públicas, mas o detalhamento completo de seus critérios foge aos objetivos do presente trabalho. Entretanto, como o déficit habitacional é o indicador oficial adotado pelo governo federal brasileiro, seus pressupostos e conceitos serão mais comentados e referenciados ao longo deste artigo, do que outras metodologias.
} 
precária em áreas sem infraestrutura adequada e, nesses termos, nos critérios da FJP (FJP; BRASIL, 2009), a inadequação das residências considera também o atendimento por sistemas adequados de abastecimento de água, esgoto e energia elétrica.

Por fim, a privacidade dos moradores, que é o ponto central do presente artigo, é comumente explorada pela presença de duas ou mais famílias na residência, pelo total de residentes no domicílio e pelo total de dormitórios. Quesitos adicionais podem ser analisados ou explorados que, não raro, consideram o tamanho físico das moradias e cômodos, a exemplo de quesitos incluídos no suplemento da PNAD de 2005, e a composição das famílias, a serem explorados no presente artigo e já abordados por Ricci (1973). As estimativas da FJP (FJP; BRASIL, 2009) abordam a privacidade interna dos moradores por meio de dois indicadores: a presença de duas ou mais famílias no domicílio, calculada pelo total de famílias conviventes; e a média de moradores por dormitório.

Os critérios para a identificação da existência de duas ou mais famílias no domicílio foi ponto de intensas discussões acadêmicas, por vezes acaloradas, que envolveram, principalmente, o critério de identificação de uma família pelo IBGE, que, concebido para caracterizar as relações de parentesco entre os membros de um mesmo domicílio, não tinha por proposta estimar a demanda por residências (FJP, 2006; ALVES; CAVENAGHI, 2006). Essas questões foram, até o momento, contornadas com a inclusão de três novos quesitos nos questionários da PNAD que exploram o desejo das famílias secundárias em constituir uma nova moradia. Nas estimativas mais recentes verificou-se que entre 55\% e 83\% das famílias conviventes desejam constituir novos domicílios, o que diminuiu o déficit habitacional por incremento em aproximadamente 1,7 milhão de moradias (FJP; BRASIL, 2009). Nesses termos, até o Censo Demográfico de 2010, a qualificação do déficit no quesito coabitação estava momentaneamente contornado com os três novos quesitos da PNAD. Entretanto, o quesito sobre a relação de parentesco entre os membros das famílias foi suprimido dos questionários do Censo, mantendo-se apenas as relações com o chefe do domicílio, significando que a identificação dos domicílios estendidos demandará revisões futuras.

No caso da densidade domiciliar, segundo os critérios comumente utilizados na construção de indicadores de necessidades habitacionais, os domicílios superlotados seriam aqueles em que a razão entre ocupantes e dormitórios excede determinado limite (INDEC, 2003; RICCI, 1973; FJP; BRASIL, 2009). No critério adotado pelas políticas de habitação do governo federal, aqueles domicílios com mais de três moradores por dormitório seriam considerados superlotados. Esses índices, calculados em diferentes áreas e regiões, poderiam revelar distorções regionais e o planejamento de Estado poderia então ser priorizado.

Ricci (1973) descreve um indicador análogo frequentemente utilizado em comparações internacionais na Europa, durante a segunda metade do século XX, que é dado pela razão entre dormitórios e moradores de uma dada região e de um mesmo domicílio (equação 1). Os indicadores $I_{i}$ e $I$ expressam, respectivamente, a densidade domiciliar do i-ésimo domicílio e do total de $n$ domicílios de uma coletividade. Obviamente o indicador regional (I) não atesta se a i-ésima família está adequadamente atendida por sua moradia, mas compara as regiões 
dentro de um Estado ou nação. Para contornar essa lacuna, o autor sugere que se compare o número de moradores com o número de dormitórios necessários para determinada família e com o número de dormitórios existentes na residência. Para a definição de critérios de dormitórios necessários, Ricci (1973) sugere os adotados na Holanda pelo Nederlandse Economische Institut (JONGE, 1963, apud RICCI, 1973²) e na França pelo Institut National de la Statistique el des Études Économiques (1965, apud RICCI, 1973³).

$$
\begin{aligned}
& I_{i}=d_{i} / n_{i} \\
& I=\sum_{i=1}^{n} d_{i} / \sum_{i=1}^{n} n_{i}
\end{aligned}
$$

Considerando que:

$d_{i} \quad$ Número de dormitórios no domicílio $i$

$n_{i} \quad$ Número de moradores no domicílio $i$

Pelos critérios holandeses, o número de cômodos desejados para uma residência considera o pressuposto de famílias nucleares e analisa o sexo dos filhos, atribuindo um dormitório para cada dois filhos do mesmo sexo. Nesse sentido, famílias compostas por um casal sem filhos demandariam residências com apenas um dormitório e aquelas formadas por um casal com um filho demandariam residências com apenas dois dormitório. No caso das famílias maiores, o total de dormitórios desejados é calculado combinando o número e o sexo dos filhos: famílias com dois filhos de sexos diferentes demandariam residências com três dormitórios; famílias com dois filhos de mesmo sexo demandariam apenas dois dormitórios; famílias com três ou quatro filhos demandariam pelo menos três dormitórios; e as famílias com cinco ou mais filhos demandariam, pelo menos, quatro dormitórios. Ao total de dormitórios são acrescentados dois outros cômodos de apoio, que serviriam como cozinha e sala. Nota-se, entretanto, que as questões sobre idade e composições familiares não nucleares não são captadas. Entende-se que a saída precoce da casa dos pais, no caso holandês, justificaria o pressuposto de um dormitório para cada dois filhos e também a abordagem da idade dos membros da família nuclear. Mas, no Brasil, em consequência da frequente coabitação familiar e da postergação da saída da casa dos pais, será necessário considerar um maior número de dormitórios para as famílias grandes, bem como a análise da idade dos membros.

No caso francês, o número de cômodos desejados é estimado considerando uma combinação de critérios: um cômodo para cada casal residente no domicílio; um cômodo para indivíduo solteiro, viúvo ou divorciado com mais de 19 anos, desde que não resida com seu parceiro; um cômodo para cada agregado ao domicílio, independente do sexo;

\footnotetext{
2 JONGE, L. S. J. Colloque sur de la plotique des logements sociaux. Thème 1: les besoins en logements - les méthodes d'évaluations aux Pays-Bas. EEC, Brussels, 1963.

3 INSTITUT NATIONAL DE LA STATISTIQUE EL DES ÉTUDES ÉCONOMIQUES. Logements - Immeubles (Spondage 1/2) Recensement de 1962. Paris, 1965, p. 57 et seq.
} 
um cômodo para cada duas crianças com menos de seis anos, independente do sexo; um cômodo para cada dois moradores entre sete e 18 anos, desde que sejam do mesmo sexo.

Os critérios de identificação de cômodos necessários adotados, em 1962, pela França e, em 1963, pela Holanda, aplicam-se aos objetivos deste estudo e podem ser úteis na quantificação da demanda por ampliações de moradias no Brasil. Entretanto, para a operacionalização de critérios similares para o Brasil, são necessárias adaptações às bases de dados existentes e também às atuais políticas de concessão de subsídios destinados às famílias de baixa renda.

Vale esclarecer que, pela legislação atual (BRASIL, 2010; CEF, 2010; CEF 2010a), as famílias com renda de até três salários mínimos têm direito ao subsídio na aquisição de casas com, no mínimo, 32 m² de área útil, descontando paredes, área de serviço e varandas. Para o caso dos apartamentos, a área mínima sobe para $37 \mathrm{~m}^{2}$ de área útil - mas sem o desconto dado às áreas de serviço e varandas - distribuídos em, pelo menos, um dormitório para um casal e outro dormitório para duas pessoas, além de sala, cozinha, circulação e banheiro. Essas residências deveriam ainda ter o custo máximo de R\$ 41 mil a R\$ 52 mil, em 2009, dependendo da região e unidade da federação da construção. Em síntese, nota-se que tais residências seriam consideradas pequenas e desconfortáveis para grande parte das famílias pertencentes às classes sociais mais abastadas e, nesses termos, os indicadores aqui propostos devem, dentro do possível, se contextualizar a essas políticas.

Ressalta-se ainda que as metodologias francesa e holandesa, citadas anteriormente, não abordam a existência de banheiros nas residências e os domicílios rústicos, provavelmente por se tratar de conceitos distantes do adensamento, da privacidade interna e da composição das famílias. Entretanto, para o caso brasileiro, o desenho de políticas de governo voltadas para melhoria, reforma e ampliação de moradias é concebido sob um mesmo conjunto de ações governamentais e, dessa forma, seria desejável que o indicador também detectasse o material construtivo e a existência ou não de banheiros.

\section{Critérios para a necessidade de reforma ou ampliação}

O desenvolvimento de um critério que avaliasse a quantidade de cômodos desejados para uma moradia considerou, prioritariamente, a idade e o sexo dos moradores. Como fonte de dados, utilizaram-se os valores relativos dos domicílios permanentes contabilizados pelas PNADs brasileiras de 2006, 2007 e 2008. Na apresentação de números absolutos, por outro lado, optou-se por não utilizar diretamente os valores expandidos da amostra da PNAD, pois entende-se que esses valores apresentam inflexões nas séries dos períodos estudados. Ademais, o uso dos números absolutos da PNAD, de forma comparativa, é desaconselhável, como relatado em Martine et al. (1988, p. 308):

O processo de expansão por estimativas de razão, que usa estatísticas populacionais independentes, poderia acarretar distorções nos quantitativos absolutos expandidos sem obrigatoriamente alterar as estruturas relativas da amostra nas diferentes características investigadas. 
Por esses motivos, o total de domicílios, quando apresentado em números absolutos, baseia-se na multiplicação matricial dos valores relativos da PNAD e dos absolutos da projeção da demanda por domicílios, realizada por Oliveira, Givisiez e Rios-Neto (2009).

Para a construção de um indicador que detectasse a demanda de reforma ou ampliação, foram considerados quatro pontos: necessidade de construção de dormitórios adicionais à moradia; necessidade de construção de cozinha e sala, entendidas como essenciais à residência; necessidade da construção de banheiro; e necessidade de reforma e substituição do material construtivo ou acabamento utilizado na moradia. 0 indicador proposto opta por não identificar a relação de parentesco dos membros dos domicílios, ou seja, não se aplica exclusivamente às famílias nucleares: embora essa seja uma abordagem distinta das metodologias francesa e holandesa, a não inclusão dessa relação procura captar todos os arranjos domiciliares, independente da relação de parentesco.

A primeira etapa do desenvolvimento do indicador consistiu em categorizar indivíduos segundo sexo e idade: adulto do sexo masculino (21 anos completos ou mais); adulto do sexo feminino (21 anos completos ou mais); criança com dez anos completos ou menos; adolescente do sexo masculino (entre 11 e 20 anos completos); e adolescente do sexo feminino (entre 11 e 20 anos completos). Para simplificar a denominação diferenciada por sexo e idade dada a adolescentes e adultos, adotou-se a terminologia resumida: homem e mulher ( $1 \stackrel{a}{a}$ e $2^{\underline{a}}$ categorias); criança (3aㅡ categoria); e menino e menina ( $4^{\underline{a}}$ e $5^{\underline{a}}$ categorias).

Para a categorização dos adolescentes, levou-se em conta a idade média em que meninas e meninos entram na puberdade no Brasil, que varia entre nove e 15 anos. Considerou-se, então, a idade de 11 anos o limite inferior, por entender que, ambos, já apresentem sinais de amadurecimento e desenvolvimento dos órgãos sexuais, bem como já pode ocorrer a menarca nas meninas.

Para estimar o total de dormitórios desejados assume-se que: cada casal demanda um dormitório; cada adulto, não casado, independente do sexo, demanda um dormitório; cada três crianças ou fração, independente do sexo, demandam um dormitório; e três adolescentes, ou fração, do mesmo sexo, demandam um dormitório. Para operacionalização desses critérios, estimou-se a necessidade de dormitórios para cada uma das categorias de morador e para cada casal, sendo que o total de dormitórios necessários é dado pela equação (3).

$d^{\prime}=d^{\prime}(1)+d^{\prime}(2)+d^{\prime}(3)+d^{\prime}(4)+d^{\prime}(5)+d^{\prime}(\mathrm{c})-d^{\prime}(\mathrm{c})^{\star} 2$

Considerando que:

d'(1) Número de dormitórios necessários para abrigar os homens do domicílio

d'(2) Número de dormitórios necessários para abrigar as mulheres do domicílio

d’(3) Número de dormitórios necessários para abrigar as crianças do domicílio

d’(4) Número de dormitórios necessários para abrigar os meninos do domicílio

d’(5) Número de dormitórios necessários para abrigar as meninas do domicílio

d'(c) Número de dormitórios necessários para abrigar os casais do domicílio

d' Número de dormitórios necessários para abrigar a família domiciliar 
Em relação ao critério de idade adotado na identificação de crianças (dez anos ou menos), um ponto a ser destacado é o sexo, pois, em curto prazo, a criança pertencerá a um grupo etário para o qual a informação sobre o sexo é importante, fator que poderia limitar a aplicação do indicador. Reconhece-se que os critérios descritos por Ricci (1973) sugerem residências mais confortáveis ao considerar crianças, independente do sexo (Holanda), ou ao identificar adolescentes em idades mais jovens (França). Entretanto, o presente trabalho procurou ser coerente com as características das habitações brasileiras, que possuem, em relação aos critérios aqui adotados, uma elevada proporção de moradias inadequadas. Outro ponto considerado refere-se às atuais políticas habitacionais, que pressupõem que residências com quatro cômodos são suficientes para as famílias de baixa renda e o uso de critérios generosos inviabilizaria a aplicação dos indicadores nas políticas públicas de habitação. Dessa forma, ressalta-se que a dinâmica e o ciclo de vida das famílias não devem ser ignorados e que o presente indicador deverá ser continuamente estimado de forma a captar esse ciclo. Da mesma forma, a necessidade de dormitórios para adolescentes e crianças, imputada neste trabalho como um dormitório para cada três indivíduos, pode precisar de revisões futuras, dependendo da formação do pesquisador e dos objetivos do estudo.

Outra dificuldade que poderia ser levantada, e que é inerente aos critérios para identificação de casais que vivem juntos, é a inexistência, nas PNADs, de uma variável sobre estado civil. O critério adotado pelos franceses utiliza quesitos sobre estado civil e local de moradia dos dois membros do casal. Para contornar a ausência deste quesito, fez-se uso da identificação das famílias conviventes residentes no domicílio, o que ocorre quando quaisquer dois ou mais membros são ligados por laços de parentesco de primeiro grau ou por um casamento. Por esses critérios, em um domicílio onde residam pai, mãe, filho e nora, por exemplo, identificam-se duas famílias e, nesse caso, a relação de parentesco da segunda família (chefe e cônjuge) mostra a necessidade de, pelo menos, dois dormitórios. Outro exemplo são os domicílios formados por quatro pessoas, sendo pai, mãe, filha e neto, o que, pelos critérios aqui adotados, indica a necessidade de três quartos. Assim, segundo os critérios assumidos, todo adulto demanda um dormitório exclusivo, exceto se esse adulto for identificado como cônjuge da pessoa de referência de uma família. Essa solução revelouse robusta e capaz de identificar todos os casais, de sexos distintos, residentes em um mesmo domicílio. Por fim, outra lacuna que vale comentários refere-se à impossibilidade de identificação de casais homoafetivos por meio dos dados da PNADs, sendo, por este motivo, imputado um dormitório para cada adulto do mesmo sexo, independente da relação com a pessoa de referência.

A Tabela 1 apresenta os 20 tipos de famílias domiciliares mais comuns no Brasil e a estimativa do total de dormitórios desejados, calculada segundo a equação (3), que será comparada com o número existente nos domicílios. Identificaram-se, na PNAD de 2008 , mais de 2.000 tipos de famílias categorizadas pelos critérios aqui definidos. Os tipos mais frequentes foram de famílias formadas por um casal (12,6\%) e por um casal e um filho (8,0\%), seguidos por estruturas unipessoais uma mulher $(6,1 \%)$ e um homem $(5,8 \%)$. 
TABELA 1

Distribuição dos domicílios, segundo tipos de famílias e dormitórios necessários Brasil - 2008

\begin{tabular}{|c|c|c|c|}
\hline \multirow{2}{*}{ Tipos de família } & \multirow{2}{*}{$\begin{array}{l}\text { Dormitórios } \\
\text { necessários }\end{array}$} & \multicolumn{2}{|c|}{ Total de domicílios } \\
\hline & & N. abs. & $\%$ \\
\hline Um casal & 1 & 7.211 .731 & 12,62 \\
\hline Um casal e uma criança & 2 & 4.596 .304 & 8,04 \\
\hline Uma mulher & 1 & 3.468 .561 & 6,07 \\
\hline Um homem & 1 & 3.325 .052 & 5,82 \\
\hline Um casal e duas crianças & 2 & 2.684 .150 & 4,70 \\
\hline Um casal e um homem & 2 & 1.630 .497 & 2,85 \\
\hline Um casal e um menino & 2 & 1.566 .099 & 2,74 \\
\hline Um homem e uma mulher & 2 & 1.460 .819 & 2,56 \\
\hline Um casal e uma menina & 2 & 1.318 .753 & 2,31 \\
\hline Um casal, um menino e uma criança & 3 & 1.243 .597 & 2,18 \\
\hline Um casal, uma menina e uma criança & 3 & 1.183 .252 & 2,07 \\
\hline Um casal, um menino e uma menina & 3 & 1.072 .039 & 1,88 \\
\hline Um casal e uma mulher & 2 & 1.063 .773 & 1,86 \\
\hline Duas mulheres & 2 & 1.043 .802 & 1,83 \\
\hline Um casal e três crianças & 2 & 669.996 & 1,17 \\
\hline Uma mulher e uma criança & 2 & 611.476 & 1,07 \\
\hline Um casal e dois meninos & 2 & 569.753 & 1,00 \\
\hline Um casal, uma mulher e um homem & 3 & 561.111 & 0,98 \\
\hline Uma mulher e uma menina & 2 & 554.792 & 0,97 \\
\hline Uma mulher e um menino & 2 & 534.575 & 0,94 \\
\hline Outros tipos & & 20.779 .620 & 36,36 \\
\hline Total & & 57.149 .753 & 100,00 \\
\hline
\end{tabular}

Fonte: IBGE. Pesquisa Nacional por Amostra de Domicílios - PNAD 2008; Oliveira, Givisiez e Rios-Neto (2009).

A Tabela 2 apresenta, para 2008, uma situação de contingência, contendo o número de dormitórios necessários e o número de dormitórios existentes. Segundo a aplicação direta dos resultados da equação (3) e a comparação com o total de dormitórios necessários, 35\% dos domicílios brasileiros seriam categorizados como necessidade de ampliação. A estimativa de que aproximadamente a terça parte das moradias brasileiras precisa de, pelos menos, um dormitório adicional pode ser considerada muito alta. Nesse sentido, poder-se-ia argumentar que existam domicílios com cômodos disponíveis para utilização como dormitórios de forma permanente, mas que, por motivos particulares de cada família, não são. Nesses casos, tais domicílios não deveriam ser contabilizados como necessidade de ampliação, o que diminuiria a estimativa de demanda de dormitórios. Mas essa suposição é improvável, além de difícil constatação com base apenas nos quesitos das pesquisas domiciliares. Dito de outra forma, é improvável que haja cômodos ociosos e que a família prefira viver em 
situações mais desconfortáveis relativamente àquelas apresentadas como critérios mínimos neste trabalho. Por outro lado, é mais provável que esses cômodos, supostamente ociosos, sejam insalubres ou que estejam destinados a atividades distintas daquelas diretamente associadas às funções mínimas de uma moradia, ou seja, descanso, alimentação e higiene. Entre essas utilizações alternativas prováveis, citam-se: atividades econômicas, de lazer, escritórios domésticos, jardins internos, despensas, oficinas domésticas, entre outros usos.

TABELA 2

Distribuição de domicílios, por dormitórios necessários, segundo dormitórios existentes Brasil - 2008

Em porcentagem

\begin{tabular}{|c|c|c|c|c|c|c|c|c|c|}
\hline \multirow{2}{*}{$\begin{array}{l}\text { Dormitórios } \\
\text { existentes }\end{array}$} & \multicolumn{8}{|c|}{ Dormitórios necessários } & \multirow[b]{2}{*}{ Total } \\
\hline & 1 & 2 & 3 & 4 & 5 & 6 & 7 & $\begin{array}{l}\text { Mais } \\
\text { de } 7\end{array}$ & \\
\hline 1 & 24,1 & 8,4 & 1,9 & 0,4 & 0,1 & 0,0 & 0,0 & 0,0 & 34,9 \\
\hline 2 & 1,5 & 25,6 & 12,2 & 3,4 & 0,7 & 0,2 & 0,0 & 0,0 & 43,6 \\
\hline 3 & 0,0 & 3,0 & 9,4 & 4,5 & 1,3 & 0,4 & 0,1 & 0,1 & 18,8 \\
\hline 4 & 0,0 & 0,1 & 0,6 & 1,0 & 0,5 & 0,2 & 0,1 & 0,0 & 2,4 \\
\hline 5 & 0,0 & 0,0 & 0,0 & 0,1 & 0,1 & 0,1 & 0,0 & 0,0 & 0,3 \\
\hline 6 & 0,0 & 0,0 & 0,0 & 0,0 & 0,0 & 0,0 & 0,0 & 0,0 & 0,0 \\
\hline 7 & 0,0 & 0,0 & 0,0 & 0,0 & 0,0 & 0,0 & 0,0 & 0,0 & 0,0 \\
\hline 8 & 0,0 & 0,0 & 0,0 & 0,0 & 0,0 & 0,0 & 0,0 & 0,0 & 0,0 \\
\hline 9 & 0,0 & 0,0 & 0,0 & 0,0 & 0,0 & 0,0 & 0,0 & 0,0 & 0,0 \\
\hline Total & 25,6 & 37,1 & 24,1 & 9,4 & 2,7 & 0,9 & 0,2 & 0,1 & 100,0 \\
\hline
\end{tabular}

Necessidade

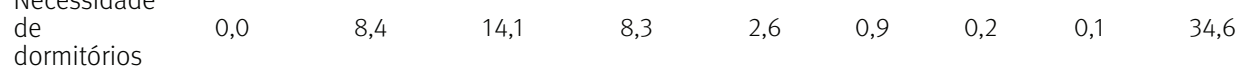

dormitórios

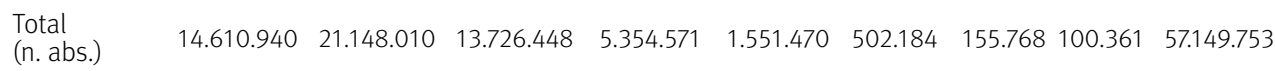
Necessidade de (n. abs.)

Fonte: IBGE. Pesquisa Nacional por Amostra de Domicílios - PNAD 2008; Oliveira, Givisiez e Rios-Neto (2009). Nota: Todos os domicílios onde são necessários mais de sete dormitórios não possuem dormitórios suficientes. Pearson Chi-Square $5.18 \times 10^{7}(\mathrm{P}=0.00)$.

Para a definição do total de cômodos de apoio (sala e cozinha) necessários, partese da definição de que cômodos são todos os compartimentos cobertos "por um teto e limitado por paredes, que fossem parte integrante do domicílio particular permanente, com exceção de corredor, alpendre, varanda aberta, garagem, depósito e outros compartimentos utilizados para fins não residenciais” (IBGE, 2008, p. 16). Dessa forma, as áreas de serviço são contabilizadas, pelos critérios das pesquisas brasileiras, como cômodos quando essas estão “limitadas por paredes e cobertas por um teto”. Ou seja, na maioria das casas, áreas de serviço não são cômodos e, na maioria dos apartamentos, áreas de serviço são cômodos. Entretanto, essa observação não deve ser generalizada, uma vez que algumas 
casas podem ter cômodos fechados para uso de área de serviço e alguns apartamentos podem ter áreas de serviços no formato de alpendres. Ademais, tanto em casas quanto em apartamentos, podem-se encontrar áreas de serviços compartilhando espaços de cozinhas e banheiros. Suposições similares podem ser desenvolvidas para vários outros espaços de uso nas moradias que poderiam ser categorizados ou não como cômodos e que, no limite, inviabilizariam a construção de um indicador de necessidades de ampliações. Mas entende-se que essas suposições estariam ausentes de certezas e, por esse motivo, o número mínimo de cômodos de apoio necessários será fixado em dois, que corresponderiam, teoricamente, a uma sala e uma cozinha.

Dessa forma, domicílios com menos de dois cômodos, desconsiderando aqueles usados como dormitórios e banheiros, serão categorizados como demandantes de ampliação. Ou seja, o total de cômodos de apoio necessários (sala e cozinha) foi fixado em dois, e o total existente de cômodos de apoio é dado pela diferença entre o total de cômodos e a soma de dormitórios, sanitários e banheiros.

A Tabela 3 apresenta a distribuição de domicílios de acordo com o número de cômodos de apoio existentes. Por esses dados, nota-se que a proporção de domicílios que demandam a construção de cômodos adicionais é de $17,8 \%$ do total de domicílios brasileiros, sendo que em $4 \%$ e $14 \%$ seria necessária a construção de um ou dois cômodos de apoio, respectivamente, entre cozinha e sala.

TABELA 3

Distribuição de domicílios, segundo número de cômodos de apoio e de banheiros existentes Brasil - 2008

\begin{tabular}{|c|c|}
\hline Número de cômodos de apoio (cozinha e sala) & Domicílios (\%) \\
\hline 0 & 3,6 \\
\hline 1 & 14,3 \\
\hline 2 & 35,3 \\
\hline 3 & 24,3 \\
\hline 4 ou mais & 22,5 \\
\hline Necessidade de cômodos & 17,8 \\
\hline Total & 100,0 \\
\hline Total (n. abs.) & 57.149 .753 \\
\hline Número de banheiros existentes & Domicílios (\%) \\
\hline 0 & 4,8 \\
\hline 1 ou mais & 95,2 \\
\hline Necessidade de banheiros & 4,8 \\
\hline Total & 100,0 \\
\hline Total (n. abs.) & 57.149 .753 \\
\hline
\end{tabular}

Fonte: IBGE. Pesquisa Nacional por Amostra de Domicílios - PNAD 2008; Oliveira, Givisiez e Rios-Neto (2009). 
Com relação ao número mínimo de banheiros, considerou-se imprescindivel a existência de pelo menos um banheiro em cada domicílio. Reconhece-se que apenas um banheiro seria insuficiente para famílias muito grandes, entretanto, devido à ausência de critérios de referências para esse quesito, assume-se um banheiro como a necessidade mínima das moradias. A Tabela 3 apresenta a proporção de domicílios sem banheiros, estimada em 5\% do total de domicílios do país.

Por fim, é também pertinente a avaliação dos materiais predominantes na execução de paredes e tetos. Nesse caso, foram consideradas inadequadas as paredes não construídas em madeira aparelhada ou alvenaria. Da mesma forma, foram incluídos como inadequados os domicílios com coberturas que não fossem de laje, cerâmica ou madeira aparelhada. Entretanto, como já observado anteriormente, os critérios de rusticidade dos domicílios são conceitualmente distintos do total e tipo de cômodos necessários para abrigar determinada família. Assim, para distinguir conceitos, o indicador final para a necessidade de reforma e ampliações será desagregado em necessidade de ampliação e necessidade de reforma ou ampliação. Dessa forma, o primeiro indicador considera a composição da família e o total de salas, cozinhas, banheiros e dormitórios da residência e, ao segundo indicador, acrescenta-se a necessidade de reforma, ou seja, a substituição de material de execução de paredes e coberturas. Em termos relativos, esses critérios são menos expressivos do que aqueles analisados até então, e nota-se que, no Brasil, 1,8\% dos domicílios demandariam substituição do material de acabamento das paredes ou coberturas.

A Tabela 4 apresenta as necessidades parciais e totais utilizadas na construção do indicador sintético, segundo as unidades da federação. Por essa tabela, é possível entender que a necessidade de reforma ou ampliação é construída pela união dos diversos conjuntos de domicílios, categorizados pelos critérios anteriormente apresentados. Nota-se que a necessidade de dormitórios é a que mais impacta na totalização do indicador de reforma ou ampliação. A análise isolada da necessidade de reforma indica, para a maioria dos Estados brasileiros, uma pequena proporção de domicílios categorizados como precários e, dessa forma, tal necessidade tem pequeno impacto relativo na estimativa do indicador final. Entretanto, os níveis de precariedade das moradias não são desprezíveis em algumas unidades da federação, destacando-se, nesse caso, a maioria dos Estados da Região Norte, em especial o Amazonas e o Acre, alguns Estados do Nordeste, em especial Maranhão, Piauí e Ceará, e os Estados do Sul. 
TABELA 4

Distribuição dos domicílios com algum tipo de necessidade Brasil - 2008

Em porcentagem

\begin{tabular}{|c|c|c|c|c|c|c|c|}
\hline \multirow[b]{2}{*}{ Estados } & \multicolumn{3}{|c|}{ Necessidade de } & \multirow{2}{*}{$\begin{array}{c}\text { Necessidade } \\
\text { de } \\
\text { ampliação }\end{array}$} & \multirow{2}{*}{$\begin{array}{c}\text { Necessidade } \\
\text { de } \\
\text { reforma }\end{array}$} & \multirow{2}{*}{$\begin{array}{l}\text { Necessidade } \\
\text { de reforma } \\
\text { ou ampliação }\end{array}$} & \multirow[b]{2}{*}{ Total } \\
\hline & Dormitórios & $\begin{array}{l}\text { Cômodos } \\
\text { de apoio }\end{array}$ & Banheiros & & & & \\
\hline Brasil & 34,7 & 17,8 & 4,8 & 45,5 & 3,2 & 46,4 & 100,0 \\
\hline Norte & 47,1 & 32,3 & 10,8 & 63,2 & 7,0 & 64,6 & 100,0 \\
\hline Rondônia & 32,0 & 21,4 & 4,5 & 45,6 & 6,9 & 48,2 & 100,0 \\
\hline Acre & 48,9 & 37,1 & 16,3 & 66,9 & 21,6 & 71,3 & 100,0 \\
\hline Amazonas & 55,5 & 37,5 & 7,7 & 69,9 & 9,6 & 71,8 & 100,0 \\
\hline Roraima & 52,2 & 45,4 & 6,2 & 73,9 & 4,5 & 74,3 & 100,0 \\
\hline Pará & 48,3 & 34,2 & 13,1 & 65,0 & 4,8 & 65,8 & 100,0 \\
\hline Amapá & 51,9 & 30,4 & 1,5 & 66,5 & 3,4 & 67,1 & 100,0 \\
\hline Tocantins & 37,4 & 19,6 & 15,3 & 54,5 & 8,5 & 55,7 & 100,0 \\
\hline Nordeste & 40,1 & 16,6 & 11,7 & 53,2 & 5,2 & 53,9 & 100,0 \\
\hline Maranhão & 46,5 & 22,0 & 22,9 & 66,4 & 19,7 & 67,8 & 100,0 \\
\hline Piauí & 40,8 & 11,9 & 27,1 & 60,7 & 8,0 & 61,1 & 100,0 \\
\hline Ceará & 43,1 & 24,1 & 9,6 & 58,6 & 4,5 & 59,2 & 100,0 \\
\hline Rio Grande do Norte & 40,8 & 19,9 & 4,4 & 53,2 & 1,5 & 53,4 & 100,0 \\
\hline Paraíba & 38,4 & 16,0 & 5,4 & 48,1 & 2,1 & 48,4 & 100,0 \\
\hline Pernambuco & 38,8 & 12,9 & 9,0 & 48,0 & 3,0 & 48,7 & 100,0 \\
\hline Alagoas & 40,4 & 16,3 & 11,4 & 52,7 & 2,6 & 53,1 & 100,0 \\
\hline Sergipe & 43,8 & 14,0 & 3,5 & 50,6 & 1,7 & 51,1 & 100,0 \\
\hline Bahia & 36,4 & 13,3 & 11,2 & 48,3 & 3,4 & 49,3 & 100,0 \\
\hline Sudeste & 34,1 & 17,3 & 1,2 & 43,2 & 1,2 & 43,7 & 100,0 \\
\hline Minas Gerais & 30,1 & 10,1 & 2,3 & 36,7 & 1,0 & 37,2 & 100,0 \\
\hline Espírito Santo & 31,8 & 15,1 & 1,8 & 41,2 & 2,0 & 42,2 & 100,0 \\
\hline Rio de Janeiro & 35,4 & 16,7 & 0,8 & 44,3 & 1,4 & 44,9 & 100,0 \\
\hline São Paulo & 35,6 & 21,2 & 0,7 & 46,1 & 1,1 & 46,4 & 100,0 \\
\hline Sul & 23,5 & 15,3 & 2,1 & 33,4 & 4,6 & 35,6 & 100,0 \\
\hline Paraná & 25,3 & 14,2 & 1,9 & 34,1 & 3,6 & 35,8 & 100,0 \\
\hline Santa Catarina & 20,5 & 14,0 & 1,3 & 29,5 & 3,6 & 31,1 & 100,0 \\
\hline Rio Grande do Sul & 23,5 & 16,9 & 2,7 & 34,8 & 6,1 & 37,9 & 100,0 \\
\hline Centro-oeste & 30,5 & 17,2 & 2,2 & 41,1 & 1,0 & 41,4 & 100,0 \\
\hline Mato Grosso do Sul & 32,2 & 17,4 & 1,3 & 40,8 & 0,9 & 41,1 & 100,0 \\
\hline Mato Grosso & 31,1 & 20,8 & 4,0 & 45,3 & 2,6 & 45,9 & 100,0 \\
\hline Goiás & 28,1 & 13,5 & 2,1 & 36,9 & 0,4 & 37,1 & 100,0 \\
\hline Distrito Federal & 34,2 & 21,7 & 0,8 & 46,5 & 0,8 & 46,7 & 100,0 \\
\hline
\end{tabular}

Fonte: IBGE. Pesquisa Nacional por Amostra de Domicílios - PNAD 2008; Oliveira, Givisiez e Rios-Neto (2009). 


\section{Resultados}

A Tabela 5 apresenta a proporção de domicílios com necessidade de reforma ou ampliações. Por esses resultados, em 2008, 46\% dos domicílios brasileiros (26,5 milhões) demandavam reformas ou ampliações. As maiores proporções são observadas no Norte do país, com $65 \%$ ou 2,6 milhões dos domicílios da região apresentando esse tipo de necessidade. A tabela indica, ainda, que a proporção de domicílios que necessitam de ampliações ou reformas diminuiu de 50\%, em 2006, para 46\%, em 2008. Essa queda é consistente em todas as regiões do país, mas a alta proporção estimada sugere que o indicador esteja rigoroso em excesso na suposição das demandas das famílias. Nesses termos, entende-se que propor um indicador que identifica necessidade de reformas para a metade dos domicílios brasileiros inviabiliza o desenho de políticas públicas focalizadas e a criação de linhas de financiamentos para reformas e ampliações. Dessa forma, há que se qualificar com maior detalhe o tipo de ampliação necessária em cada domicílio e identificar aqueles que demandam reformas mais prioritárias entre os 26,5 milhões de domicílios que, em 2008, precisavam, teoricamente, de reformas.

TABELA 5

Domicílios com necessidade de reforma ou ampliação

Brasil - 2006-2008

\begin{tabular}{|c|c|c|c|c|c|c|}
\hline \multirow{2}{*}{ Regiões } & \multicolumn{2}{|c|}{2006} & \multicolumn{2}{|c|}{2007} & \multicolumn{2}{|c|}{2008} \\
\hline & N. abs. & $\%$ & N. abs. & $\%$ & N. abs. & $\%$ \\
\hline Brasil & 26.464 .385 & 49,8 & 27.183 .807 & 49,2 & 26.503 .664 & 46,4 \\
\hline Norte & 2.536 .401 & 69,0 & 2.671 .972 & 69,2 & 2.607 .791 & 64,6 \\
\hline Nordeste & 8.060 .030 & 58,9 & 8.220 .748 & 57,7 & 7.973 .075 & 53,9 \\
\hline Sudeste & 10.808 .805 & 46,2 & 11.080 .448 & 45,8 & 10.885 .813 & 43,7 \\
\hline Sul & 3.291 .798 & 38,9 & 3.386 .353 & 38,5 & 3.243 .866 & 35,6 \\
\hline Centro-oeste & 1.788 .561 & 45,2 & 1.859 .272 & 45,0 & 1.778 .286 & 41,4 \\
\hline
\end{tabular}

Fonte: IBGE. Pesquisa Nacional por Amostra de Domicílios - PNAD 2008; Oliveira, Givisiez e Rios-Neto (2009).

Para melhor qualificar o indicador proposto, inicialmente parte-se da constatação de que a necessidade de ampliação é a que mais contribui na categorização final de um domicílio como inadequado (Tabela 4). Uma forma de melhor qualificar essa demanda seria pelo cruzamento das informações sobre a quantidade demandada de cômodos, dormitórios e banheiros. A Tabela 6 apresenta o cruzamento entre as necessidades para os três tipos de cômodos usados como referência nesses critérios, contabilizando apenas a necessidade de ampliação. Para estimar a necessidade de reforma seria necessário unir o conjunto de domicílios que necessitam de ampliação com o daqueles que precisam de reformas. Ou seja, a necessidade de reforma corresponde a uma quarta dimensão a ser acrescentada à tabela. As células dessa matriz de três dimensões revelam questões capazes de qualificar em níveis o indicador de ampliações. Por exemplo, os domicílios que não demandam a construção de banheiros, dormitórios e cômodos, que representam 54,5\% do total, são 
aqueles considerados adequados pelos critérios definidos neste estudo. No extremo oposto, os domicílios que precisam da construção de sala, cozinha, mais de três dormitórios e ainda um banheiro, concomitantemente, representam 0,0\% do total dos domicílios brasileiros e podem ser considerados aqueles em situação mais graves.

TABELA 6

Contingência entre a necessidade de cômodos de apoio e de dormitórios e banheiros. Brasil - 2008

Em porcentagem

\begin{tabular}{|c|c|c|c|c|}
\hline \multirow{2}{*}{$\begin{array}{l}\text { Necessidade de banheiros e } \\
\text { dormitórios }\end{array}$} & \multicolumn{3}{|c|}{ Necessidade de cômodos de apoio } & \multirow{2}{*}{ Total } \\
\hline & Nenhum & Um & Dois & \\
\hline \multicolumn{5}{|l|}{$\begin{array}{l}\text { Nenhum banheiro } \\
\text { Dormitórios }\end{array}$} \\
\hline Nenhum & 54,5 & 6,8 & 1,5 & 62,8 \\
\hline Um & 18,6 & 4,6 & 0,9 & 24,1 \\
\hline Dois & 4,6 & 1,5 & 0,4 & 6,5 \\
\hline Três & 1,0 & 0,4 & 0,1 & 1,5 \\
\hline Mais de três & 0,3 & 0,1 & 0,0 & 0,4 \\
\hline Subtotal & 79,0 & 13,4 & 2,9 & 95,3 \\
\hline \multicolumn{5}{|l|}{$\begin{array}{l}\text { Um banheiro } \\
\text { Dormitórios }\end{array}$} \\
\hline Nenhum & 1,8 & 0,4 & 0,3 & 2,5 \\
\hline Um & 1,0 & 0,4 & 0,2 & 1,6 \\
\hline Dois & 0,3 & 0,1 & 0,1 & 0,5 \\
\hline Três & 0,1 & 0,0 & 0,0 & 0,1 \\
\hline Mais de três & 0,0 & 0,0 & 0,0 & 0,0 \\
\hline Subtotal & 3,2 & 0,9 & 0,6 & 4,7 \\
\hline Total & 82,2 & 14,3 & 3,5 & 100,0 \\
\hline \multirow{8}{*}{ Totalização das necessidades } & \multicolumn{3}{|c|}{ Sem necessidades de ampliação } & 54,5 \\
\hline & \multicolumn{3}{|c|}{ Nível 1} & 30,0 \\
\hline & \multicolumn{3}{|c|}{ Nível 2} & 8,9 \\
\hline & \multicolumn{3}{|c|}{ Nível 3} & 1,5 \\
\hline & \multicolumn{3}{|c|}{ Nível 4} & 0,4 \\
\hline & \multicolumn{3}{|c|}{ Nivel 5} & 1,8 \\
\hline & \multicolumn{3}{|c|}{ Nível 6} & 2,3 \\
\hline & \multicolumn{3}{|c|}{ Nível 7} & 0,6 \\
\hline
\end{tabular}

Fonte: IBGE. Pesquisa Nacional por Amostra de Domicílios - PNAD 2008; Oliveira, Givisiez e Rios-Neto (2009)

Como sugestão foram identificados, com base na matriz apresentada na Tabela 6, níveis numerados em uma escala de zero a sete, sendo que zero identifica os domicílios sem demanda de ampliações e sete aqueles que necessitam as maiores reformas. Nesses termos, o nível 1 (30,0\%) corresponde à soma dos domicílios que demandam a construção de um dormitório e nenhum cômodo de apoio (18,6\%), ou de um cômodo de apoio e nenhum dormitório (6,8\%), ou de um cômodo de apoio e um dormitório (4,6\%). Ou seja, o nível 1 corresponderia à necessidade mais branda de ampliação entre os sete apresentados. Assim, uma política pública que disponibilizasse recursos para reformas poderia ser focalizada, por 
exemplo, entre os níveis 2 e 7, que totalizam 15,6\% dos domicílios (8,9 milhões). Note-se que os níveis 5, 6 e 7 correspondem a todos os domicílios que demandam banheiros, sendo que o nível 5 (1,8\%), por exemplo, representa aqueles domicílios que necessitam da construção de um banheiro, mas possuem cômodos e dormitórios suficientes para abrigar a família.

Nessa linha de raciocínio, as famílias conviventes poderiam ser analisadas sob outra ótica, conforme apresentado na Tabela 7. Existiriam, em 2008, cerca 2,4 milhões de domicílios (4,3\%) com necessidade de ampliação e com mais de uma família convivendo, ou seja, o número é superior aos 1,7 milhão de moradias estimadas para 2008 pelo déficit habitacional (FJP, 2009). Entretanto, o cruzamento do número de famílias em cada domicílio com os níveis de necessidades sugeridos neste trabalho mostra que, mesmo entre os domicílios sem necessidade de intervenção, encontram-se situações de coabitação familiar (0,9\%). Observase também que o maior percentual é verificado na situação de duas famílias conviventes e o nível 1 de necessidade.

TABELA 7

Distribuição dos domicílios, densidade excessiva e existência de famílias conviventes, segundo níveis de necessidade de ampliação

Brasil - 2008

\begin{tabular}{lccc}
\hline \multicolumn{1}{c}{ Níveis de necessidade de ampliação } & $\begin{array}{c}\text { Densidade } \\
\text { excessiva }\end{array}$ & $\begin{array}{c}\text { Famílias } \\
\text { conviventes }\end{array}$ & $\begin{array}{c}\text { Em porcentagem } \\
\text { dotal de } \\
\text { domílios }\end{array}$ \\
\hline Sem necessidade de ampliação & 0,0 & 0,9 & 54,5 \\
Nível 1 & 1,4 & 1,9 & 30,0 \\
Nível 2 & 1,6 & 1,3 & 8,9 \\
Nível 3 & 0,6 & 0,5 & 1,5 \\
Nível 4 & 0,3 & 0,3 & 0,4 \\
Nível 5 & 0,0 & 0,0 & 1,8 \\
Nível 6 & 0,5 & 0,2 & 2,3 \\
Nível 7 & 0,2 & 0,1 & 0,6 \\
\hline Subtotal necessidade de ampliação & $\mathbf{4 , 6}$ & $\mathbf{4 , 3}$ & $\mathbf{4 5 , 5}$ \\
\hline Total & $\mathbf{4 , 6}$ & $\mathbf{5 , 1}$ & $\mathbf{1 0 0 , 0}$ \\
N. abs. & $\mathbf{2 . 6 0 0 . 4 9 5}$ & $\mathbf{2 . 9 3 9 . 9 0 2}$ & $\mathbf{5 7 . 1 4 9 . 7 5 3}$ \\
\hline
\end{tabular}

Fonte: IBGE. Pesquisa Nacional por Amostra de Domicílios - PNAD (2008); Oliveira, Givisiez e Rios-Neto (2009)

A Tabela 7 também apresenta a relação entre o indicador de densidade excessiva de moradores por dormitório, segundo os critérios utilizados pela FJP (2006), e o indicador de necessidade de ampliações, em seus sete níveis. Observa-se que 54,5\% dos domicílios não são considerados adensados ou com necessidade de ampliação e 45,5\% são classificados como inadequados nos dois critérios analisados. Entretanto, o resultado mais expressivo relaciona-se aos 30,0\% de domicílios categorizados no nível 1, mas com apenas 1,4\% apresentando densidade excessiva.

Finalmente, a Tabela 8 sugere a distribuição dos domicílios, em cada nível de necessidade de ampliação, segundo os Estados brasileiros. A melhor situação é verificada na Região Sul 
(67\%), seguida pelo Centro-Oeste (59\%), Sudeste (57\%), Nordeste (47\%) e, por último, o Norte, onde apenas 37\% dos domicílios são adequados. Entre os Estados, a melhor situação é identificada em Santa Catarina, com 70\% dos domicílios em condições adequadas. Na outra ponta encontra-se Roraima, onde somente $26 \%$ dos domicílios situam-se no nível zero de necessidade de reforma ou ampliação.

TABELA 8

Distribuição dos domicílios, por nível de necessidade de ampliação Brasil - 2008

Em porcentagem

\begin{tabular}{|c|c|c|c|c|c|c|c|c|c|}
\hline \multirow{2}{*}{ Unidade Territorial } & \multicolumn{8}{|c|}{ Níveis de necessidade de ampliação } & \multirow{2}{*}{ Total } \\
\hline & 0 & 1 & 2 & 3 & 4 & 5 & 6 & 7 & \\
\hline Brasil & 54,5 & 30,0 & 8,8 & 1,5 & 0,5 & 1,8 & 2,3 & 0,7 & 100,0 \\
\hline Norte & 36,8 & 33,0 & 15,6 & 2,8 & 1,0 & 2,8 & 5,4 & 2,6 & 100,0 \\
\hline Rondônia & 54,4 & 29,9 & 9,3 & 1,4 & 0,5 & 1,7 & 2,0 & 0,8 & 100,0 \\
\hline Acre & 33,1 & 30,4 & 17,5 & 2,0 & 0,8 & 3,8 & 7,2 & 5,3 & 100,0 \\
\hline Amazonas & 30,1 & 32,4 & 21,4 & 5,7 & 2,7 & 1,3 & 4,3 & 2,1 & 100,0 \\
\hline Roraima & 26,1 & 40,7 & 22,3 & 3,8 & 0,9 & 1,6 & 2,6 & 2,0 & 100,0 \\
\hline Pará & 35,0 & 33,4 & 15,3 & 2,4 & 0,8 & 3,0 & 6,7 & 3,4 & 100,0 \\
\hline Amapá & 33,5 & 43,4 & 19,1 & 1,7 & 0,9 & 0,5 & 0,3 & 0,7 & 100,0 \\
\hline Tocantins & 45,5 & 30,3 & 8,0 & 1,0 & 0,1 & 7,3 & 7,1 & 0,9 & 100,0 \\
\hline Nordeste & 46,8 & 29,4 & 9,6 & 1,8 & 0,7 & 5,0 & 5,5 & 1,2 & 100,0 \\
\hline Maranhão & 33,6 & 30,1 & 10,4 & 1,9 & 1,1 & 9,5 & 10,9 & 2,6 & 100,0 \\
\hline Piauí & 39,3 & 26,0 & 5,9 & 1,4 & 0,4 & 13,8 & 12,2 & 1,1 & 100,0 \\
\hline Ceará & 41,4 & 34,7 & 11,9 & 1,7 & 0,7 & 3,4 & 4,9 & 1,3 & 100,0 \\
\hline Rio Grande do Norte & 46,8 & 35,1 & 11,3 & 1,6 & 0,8 & 1,6 & 2,1 & 0,7 & 100,0 \\
\hline Paraíba & 51,9 & 30,8 & 10,0 & 1,3 & 0,6 & 2,0 & 2,7 & 0,7 & 100,0 \\
\hline Pernambuco & 52,0 & 26,8 & 9,1 & 2,2 & 0,9 & 3,1 & 4,6 & 1,3 & 100,0 \\
\hline Alagoas & 47,3 & 29,5 & 9,5 & 1,6 & 0,7 & 5,2 & 5,3 & 1,0 & 100,0 \\
\hline Sergipe & 49,4 & 33,8 & 10,7 & 2,0 & 0,6 & 1,4 & 1,7 & 0,3 & 100,0 \\
\hline Bahia & 51,7 & 26,2 & 8,3 & 1,9 & 0,7 & 5,4 & 4,8 & 1,0 & 100,0 \\
\hline Sudeste & 56,8 & 31,4 & 8,8 & 1,5 & 0,5 & 0,4 & 0,5 & 0,2 & 100,0 \\
\hline Minas Gerais & 63,3 & 26,5 & 6,4 & 1,1 & 0,4 & 1,1 & 1,0 & 0,2 & 100,0 \\
\hline Espírito Santo & 58,8 & 30,5 & 7,3 & 1,3 & 0,4 & 0,4 & 0,9 & 0,5 & 100,0 \\
\hline Rio de Janeiro & 55,7 & 31,9 & 9,5 & 1,6 & 0,5 & 0,1 & 0,3 & 0,4 & 100,0 \\
\hline São Paulo & 53,9 & 33,5 & 9,8 & 1,6 & 0,5 & 0,2 & 0,3 & 0,2 & 100,0 \\
\hline Sul & 66,6 & 25,7 & 4,9 & 0,6 & 0,1 & 0,7 & 1,2 & 0,2 & 100,0 \\
\hline Paraná & 65,9 & 26,6 & 4,8 & 0,6 & 0,2 & 0,5 & 1,1 & 0,2 & 100,0 \\
\hline Santa Catarina & 70,5 & 23,7 & 4,1 & 0,4 & 0,0 & 0,5 & 0,7 & 0,1 & 100,0 \\
\hline Rio Grande do Sul & 65,2 & 26,0 & 5,4 & 0,6 & 0,1 & 0,9 & 1,5 & 0,4 & 100,0 \\
\hline Centro-oeste & 58,9 & 29,6 & 7,9 & 1,1 & 0,3 & 0,8 & 1,0 & 0,4 & 100,0 \\
\hline Mato Grosso do Sul & 59,2 & 30,4 & 7,2 & 1,6 & 0,3 & 0,2 & 0,7 & 0,4 & 100,0 \\
\hline Mato Grosso & 54,7 & 31,2 & 8,9 & 0,9 & 0,3 & 1,5 & 1,9 & 0,5 & 100,0 \\
\hline Goiás & 63,1 & 27,4 & 6,3 & 1,0 & 0,2 & 0,8 & 1,0 & 0,3 & 100,0 \\
\hline Distrito Federal & 53,5 & 32,3 & 11,7 & 1,1 & 0,6 & 0,2 & 0,4 & 0,3 & 100,0 \\
\hline
\end{tabular}

Fonte: IBGE. Pesquisa Nacional por Amostra de Domicílios - PNAD 2008; Oliveira, Givisiez e Rios-Neto (2009). 


\section{Considerações finais}

Entre os achados do trabalho, destaca-se que, em um primeira análise, 46,8\% dos domicílios brasileiros demandariam reformas ou ampliações, representando 26,5 milhões de domicílios. A pior situação seria verificada na Região Norte, onde 65\% dos domicílios necessitariam de reformas ou ampliações. Contudo, em consonância com os resultados do déficit habitacional estimado pela Fundação João Pinheiro, entre 2006 e 2008, a proporção de domicílios com demanda por reformas e ampliações diminuiu de forma consistente em todas as regiões brasileiras.

Uma classificação de sete níveis de necessidades, em que zero indica nenhuma demanda de ampliação e sete identifica aqueles domicílios que precisam das maiores ampliações, evidenciou que 54,5\% dos domicílios encontram-se no nível zero. Entre os que demandam algum tipo de ampliações, a maior parte (30\%) encontra-se no nível 1, o mais brando em termos de necessidade. No extremo mais grave, apenas 0,6\% se enquadram no nível sete.

Ressalta-se, porém, que determinadas culturas, dentro do território nacional, podem demandar estruturas de moradias distintas do padrão aqui proposto de quarto, sala, cozinha e banheiro. Na região amazônica, por exemplo, não é rara a existência de residências abertas construídas em madeira, como grandes galpões, onde são distribuídos redes e os outros espaços. Nessa estrutura residencial, o banheiro, quando existente, situa-se em área externa da casa. Ou seja, esse tipo de moradia teria apenas um cômodo e, pelos critérios aqui desenvolvidos, seria categorizado como necessidade de ampliações e, provavelmente, de reformas. Sob determinadas óticas acadêmicas, a categorização de que essa residência é inadequada seria, por si só, uma visão distorcida por um padrão de arquitetura comum em cidades ocidentais típicas. Entretanto, vale ressaltar que a avaliação dos níveis de habitabilidade dessas moradias, ou se elas são adequadas ou não à cultura que as utiliza, não está em discussão neste artigo. Entende-se que esse tema deveria ser objeto de aprofundamentos em outros campos de estudos acadêmicos, como, por exemplo, arquitetura, antropologia, sociologia e saúde pública. Estudos futuros nessa temática podem focalizar nas distintas realidades do país, seja por meio da avaliação de dados de pesquisas amostrais, seja a partir de um sonhado censo predial.

Adicionalmente, apesar de o limite de três moradores por dormitório ser adotado pelos critérios do déficit habitacional da FJP (2009), acredita-se que ele seja próximo do desconforto. O trabalho de Neufert e a Planungs Ag-Neufert Mittmann Graf (1998), por exemplo, ao apresentar exemplos de projetos arquitetônicos, não sugere a existência de dormitórios com mais de duas pessoas, exceto naqueles destinados a alojamentos temporários. Mas cumpre destacar que os critérios adotados neste trabalho pretendiam ser coerentes, mesmo que parcialmente, com as prioridades definidas nas políticas habitacionais brasileiras e com os conceitos adotados para o déficit habitacional (CEF, 2010, 2010a; FJP; BRASIL, 2010). Nesse contexto, embora o indicador de necessidade de ampliação não aborde exclusivamente famílias nucleares, em estudos futuros, a identificação das relações de parentesco entre os 
membros dos domicílios pode aprofundar as dimensões estudadas ao, por exemplo, qualificar as famílias nucleares e identificar filhos e parentes próximos.

Nas palavras de Furtado (2003, p. 19), "no mundo inteiro houve e há problemas de déficit habitacional. Mas todos os países, em que houve e há políticas de financiamento da construção, resolveram parcialmente, ou pelo menos evitaram, o agravamento do problema”. Nesses termos, é fato que os programas governamentais brasileiros, nas três esferas de governo, têm, recentemente, se esforçado na produção de imóveis de baixo custo nas mais distintas regiões do país. Mas, se as políticas governamentais consideram que o padrão de casa destinado às famílias de baixa renda é suficiente para abrigar um casal e mais duas pessoas, seria incoerente exigir critérios de conforto e privacidade muito generosos para a avaliação das necessidades habitacionais brasileiras. No caso do limite de adensamento por dormitório adotado pelo déficit habitacional, de três moradores, uma casa no padrão mínimo nas diretrizes de governo seria suficiente para abrigar até seis moradores. Ou seja, seguindo esses critérios e considerando a improbabilidade de todas as famílias terem, no máximo, seis componentes, é provável que esse padrão mínimo de moradia esteja, de fato, dando continuidade a padrões de desconforto. No caso dos critérios adotados neste trabalho, essa mesma casa só seria considerada adequada para abrigar seis moradores em composições familiares muito específicas e raras, como, por exemplo, com seis crianças ou seis adolescentes de mesmo sexo, ou ainda seis adolescentes, sendo dois grupos de três indivíduos de sexos distintos.

Outro ponto importante a ser considerado é que a permanência de filhos adolescentes e adultos no ambiente familiar justifica o maior número de cômodos, independentemente de qual critério para privacidade seja adotado. Porém, incentivar reformas das moradias, por meio de linhas de financiamento, por exemplo, poderia, indiretamente, incentivar a coabitação familiar. De outro ponto de vista, poder-se-ia incentivar a saída desses filhos da casa dos pais, por meio de linhas de financiamentos de imóveis para adultos jovens ou por alterações no mercado de aluguel. Entretanto, essa segunda alternativa levanta outras questões, já que pressupõe mudança de comportamento cultural de grande parte das famílias brasileiras.

Portanto, é notório que o indicador proposto incorpora a dimensão demográfica à identificação das necessidades habitacionais, parcialmente ignorada nos indicadores atualmente em uso no Brasil. Entende-se que as políticas habitacionais devam abordar não só a construção de novas residências, mas também, de forma mais focalizada, a composição familiar e as etapas do ciclo de vida das famílias. Para isso, as ações governamentais, além da construção de casas, devem também se direcionar à reformas, ampliações, requalificação de imóveis e prestação de assistência técnica. Nesses termos, o indicador apresentado pode aumentar a eficiência da alocação de recursos públicos.

Finalmente, é fato que, pelas constatações aqui apresentadas, novas questões foram abordadas no que tange às necessidades de melhoria das moradias brasileiras, mas a inclusão das estimativas do indicador de necessidades por reformas e ampliações na construção do déficit habitacional aumentaria o montante do déficit para níveis alarmantes. Ademais, 
tendo em vista a dificuldade de se incorporarem mudanças metodológicas em indicadores já existentes e consolidados, essa não seria uma estratégia prudente. Além disso, a série histórica do déficit habitacional, que, guardadas poucas alterações conceituais, possui quase 20 anos de história, já é uma referência entre os diversos indicadores brasileiros. Assim, entende-se que o indicador aqui proposto trata-se de uma nova abordagem para exploração das questões atinentes à qualidade das moradias.

\section{Referências}

AGUIRRE, A. de B.; HENNIES, W. T. Logística para agregados (brita e areia) em grandes centros urbanos. REM: Revista Escola de Minas, v. 63, n. 4, dez. 2010.

ALVES, J. E. D.; CAVENAGHI, S. Déficit habitacional, famílias conviventes e condições de moradia. In: GUIMARÃES, J. R. (Org.). Demografia dos negócios. Campinas: Abep, 2006.

AZEREDO, C. M. et al. Avaliação das condições de habitação e saneamento: a importância da visita domiciliar no contexto do Programa de Saúde da Família. Ciência \& Saúde Coletiva, v. 12, n. 3, jun. 2007.

BARRETO, R. de O.; PAULA, A. P. P. de; GONTIJO, F. M. C. As limitações das políticas de habitação portuguesas: reflexões sobre a importância da intersetorialidade. Cadernos EBAPE.BR, v. 8, n. 4, dez. 2010 .

BELO, F. É em comum que nós habitamos. Ex ÆEquo, n. 22, p. 19-24, 2010.

BRASIL. Ministério das Cidades. Portaria № 93 de 24 fevereiro de 2010. Dispõe sobre a aquisição e alienação de imóveis sem prévio arrendamento no âmbito do Programa de Arrendamento Residencial - PAR e do Programa Minha Casa Minha Vida - PMCMV. Diário Oficial da União, Brasília, 25 de fevereiro de 2010. Disponível em: 〈http://www.cidades.gov.br/ministerio-das-cidades/legislacao/ portarias/portarias-2010/PORTARIA\%2093-10\%20-\%20\%20DIRETRIZES\%20FAR\%20\%20PMCMV. pdf〉. Acesso em: 26 jul. 2011

CEF - Caixa Econômica Federal. Especificações para empreendimentos até 3 SM: apartamentos. Brasília: CEF, 2010. Disponível em: 〈http://downloads.caixa.gov.br/_arquivos/habita/mcmv/CASAS. pdf>. Acesso em: 03 abr. 2010.

Especificações para empreendimentos até 3 SM: casas. Brasília: CEF, 2010a. Disponível em: 〈http://downloads.caixa.gov.br/_arquivos/habita/mcmv/CASAS.pdf〉. Acesso em: 03 abr. 2010.

COHEN, S. C. et al. Habitação saudável no Programa Saúde da Família (PSF): uma estratégia para as políticas públicas de saúde e ambiente. Ciência \& Saúde Coletiva, v. 9, n. 3, set. 2004.

DIAS, J. C. P. Os primórdios do controle da doença de Chagas (em homenagem a Emmanuel Dias, pioneiro do controle, no centenário de seu nascimento). Revista da Sociedade Brasileira de Medicina Tropical, Uberaba, 2011.

FEIJTEN, P.; VAN HAM, M. The impact of splitting up and divorce on housing careers in the UK. Housing Studies, v. 25, n. 4, p. 483-507, July 2010.

FIORAVANTE, E. F. Projeção de domicílios por modelo multi-estado e aplicação para previsão da frota de automóveis em Belo Horizonte. Tese (Doutorado em Demografia). Belo Horizonte: Cedeplar/ UFMG, 2009.

FJP - Fundação João Pinheiro; BRASIL. Ministério das Cidades. Secretaria Nacional de Habitação. Déficit habitacional no Brasil 2007. Brasília: Ministérios das Cidades, Secretaria Nacional de Habitação, 2009. 
FJP - Fundação João Pinheiro. Déficit habitacional no Brasil 2000. Belo Horizonte: FJP, 2001.

Déficit habitacional no Brasil 2005. Belo Horizonte: FJP, 2006.

FRANSOZO, H. L.; SOUZA, H. A. de; FREITAS, M. S. da R. Eficiência térmica de habitação de baixo custo estruturada em aço. REM: Revista Escola de Minas, v. 58, n. 2, jun. 2005.

FURTADO, C. A habitação. Estudos Avançados, v. 17, n. 48, ago. 2003.

GENEVOIS, M. L. B. P.; COSTA, O. V. Carência habitacional e déficit de moradias: questões metodológicas. São Paulo em Perspectiva, v. 1, n. 15, 2001.

GIVISIEZ, G. H. N.; RIOS-NETO, E. L. G.; SAWYER, D. Projeção da demanda demográfica por domicílios: aplicação da metodologia das taxas de chefia baseada em modelos de idade-período-coorte. In: GUIMARÃES, J. R. (Org.). Demografia dos negócios. Campinas: Abep, 2006.

GONCALVES, H. A tuberculose ao longo dos tempos. História, Ciências, Saúde-Manguinhos, v. 7, n. 2, out. 2000.

GONCALVES, R. S.; SIMOES, S. S.; FREIRE, L. de L. A contribuição da Igreja Católica na transformação da habitação popular em problema público na França e no Brasil. Cuadernos de Antropología Social, Buenos Aires, n. 31, jul. 2010.

IBGE - Instituto Brasileiro de Geografia e Estatística. Pesquisa Nacional por Amostra de Domicílios 2008: notas metodológicas. Rio de janeiro: IBGE, 2008.

INDEC - Instituo Nacional de Estadística y Censos. Mapa de necesidades básicas insatisfechas 2001. INDEC: Revista Informativa Del Censo 2001, n. 7, set. 2003. Disponível em: 〈http://www.indec.mecon. ar/nuevaweb/cuadros/74/Aqui7.pdf>. Acesso em: 03 abr. 2010.

KING, D. Official household projections in England: methodology, usage and sensitivity tests. ECEEUROSTAT work session on Demographic Projection. Perugia, Italy, 3-7 may, 1999 (Working paper, n. 47).

KRUGER, E. L.; LAROCA, C. Avaliação de desempenho térmico de protótipo de baixo custo em madeira de reflorestamento. REM: Revista Escola de Minas, v. 62, n. 4, dez. 2009.

MARICATO, E. Metrópoles desgovernadas. Estudos Avançados, v. 25, n. 71, abr. 2011.

MARTINE, G. et al. A PNAD: notas para uma avaliação. In: SAWYER, D. O. (Org.). PNADs em foco: anos 80. Brasília: Abep, 1988. Disponível em: 〈http://www.abep.nepo.unicamp.br/docs/outraspub/pnadsemfoco/ martine.pdf>. Acesso em: 14 set. 2011.

MORAIS, M. da P.; CRUZ, B. de O.; OLIVEIRA, C. W. de A. Residential segregation and social exclusion in Brazilian housing markets. Brasília: Ipea, abril de 2003 (Textos para discussão, n. 951).

MULDER, C. H.; BILLARI, F. C. Homeownership regimes and low fertility. Housing Studies, v. 25, n. 4, p. 527-541, July 2010.

MULDER, C. H.; LAUSTER, N. T. Housing and family: an introduction. Housing Studies, v. 25, n. 4, p. 433-440, July 2010.

NEUFERT, P.; PLANUNGS AG-NEUFERT MITTMANN GRAF. Arte de projetar em arquitetura. 17 ed. Barcelona: Gustavo Gili, 1998.

O’NEILL, B. C.; JIANG, L. Toward a new model for probabilistic household forecast. International Statistical Review, v. 72, n.1, p. 51-64, 2004.

OLIVEIRA, M. C. F. A. de; VIEIRA, J. M.; BARROS, L. F. W. Composição dos domicílios e núcleos familiares brasileiros: revelações da PNDS 2006. In: ENCONTRO NACIONAL DE ESTUDOS POPULACIONAIS. Anais... Caxambu-MG, 2010. Disponível em: 〈http://www.abep.nepo.unicamp.br/encontro2010/docs_pdf/ tema_12/abep2010_2075.pdf>. Acesso em: 28 jul. 2011 
OLIVEIRA, E. L. de; GIVISIEZ, G. H. N.; RIOS-NETO, E. L. G. Demanda futura por moradias no Brasil 2003-2023: uma abordagem demográfica. Brasília: Ministério das Cidades, 2009. CD-ROM.

SOUTH, S. J.; PAIS, J.; CROWDER, K. Metropolitan influences on migration into poor and nonpoor neighborhoods. Social Science Research, v. 40, p. 950-964.

PANDOLFO, A. et al. Modelo para avaliação e comparação de projetos de habitação com base no valor. Gestão \& Produção, v. 14, n. 3, dez. 2007.

PICANÇO, M. de S.; GHAVAMI, K. Comportamento à compressão de argamassas reforçadas com fibras vegetais da Amazônia. REM: Revista Escola de Minas, v. 61, n. 1, mar. 2008.

RODRÍGUEZ, J. Información censal relevante para la medición del déficit habitacional. In: CELADE - Centro Latinoamericano y Caribeño de Demografía. América Latina: aspectos conceptuales de los censos del 2000. Santiago: Cepal, 1999. (Series Manuales, n. 1). Disponível em: 〈http://www.eclac.cl/publicaciones/ DocumentosPublicaciones/4/lcl1204/lcl1204e.pdf〉. Acesso em: 28 jul. 2011.

RICCI, R. Observations on significance and use of the indices of crowing. In: UNITED NATIONS. Housing requirements and demand current methods of assessment and problems of estimation. Geneva: United Nation, 1973.

SANTOS, C. H. Políticas federais de habitação no Brasil: 1964/1998. Brasília: Ipea 1999 (Textos para discussão, n. 654).

STRÖM, S. Housing and first births in Sweden, 1972-2005. Housing Studies, v. 25, n. 4, p. 509-526, July 2010.

SOUTH, S. J.; PAIS, J.; CROWDER, K. Metropolitan influences on migration into poor and nonpoor neighborhoods. Social Science Research, v. 40, Jan. 2011.

UNITED NATIONS. Housing requirements and demand: current methods of assessment and problems of estimation. Geneva: United Nations Publication, 1973.

TAUIL, P. L. Urbanização e ecologia do dengue. Cadernos de Saúde Pública, Rio de Janeiro, 2011.

VALADARES, J. de C. Qualidade do espaço e habitação humana. Ciência \& Saúde Coletiva, v. 5, n. 1 , 2000.

VASCONCELOS, J. R. CÂNDIDO JÚNIOR, J. O. 0 problema habitacional no Brasil: déficit, financiamento e perspectivas. Rio de Janeiro: Ipea, abril de 1996 (Texto para discussão, n. 410).

YI, Z.; LAND. K. C.; WANG, Z.; DANAM, G. US family household dynamic and momentum: extension of profamy method and application. Project Demographic Tool and Database for Household Forecasting. Report No. 3 SBIR. 2004[?] Disponível em: «http://www.sabresystems.com/whitepapers/report_no_3. pdf> Acesso em: 14 set. 2011.

\section{Abstract}

Household privacy: a study of needs in remodeling or adding on to homes

Adequate housing must include spaces protected from the elements and be favorable to health, privacy, safety and security. The authors discuss homes in terms of the privacy they afford and their internal capacity to accommodate families of varying compositions with basic standards of convenience. Government programs for low-income housing should include not only the construction of new homes, but also guarantee the renovation of older residences as well, together with the corresponding technical assistance. We propose a criterion for evaluating the internal privacy of houses and suggest an indicator 
of Dwelling Extension Requirements based on the desirable number of bedrooms, other rooms and bathrooms, based on age, gender and marital status of the occupants. The proposed indicator includes seven levels of need, varying from the enlarging of a single room, at the lowest level, to the building of another bathroom and at least four rooms, at the most advanced level. The indicator can be useful in public policies for remodeling and extending residences. The results indicate that, in $2008,46 \%$ of Brazilian households needed extensions or remodeling, but the qualification of this indicator on seven levels indicates that public policies could focus, for example, on levels that would encompass approximately $16 \%$ of all Brazilian households. The highest proportion of appropriate households can be seen in the Southern Region (67\%), whereas the worst situation is in the Northern Region, where only $37 \%$ of households can be classified as adequate.

Keywords: Applied Demography. Housing. Housing deficit. Degree of crowding. Cohabitation.

\section{Resumen}

\section{Privacidad intradomiciliaria: un estudio sobre las necesidades de ampliaciones en residencias}

Una vivienda adecuada debe poseer un espacio protegido de las intemperies y presentar condiciones favorables de salubridad, privacidad y seguridad. Este artículo aborda la privacidad interna de las viviendas y su capacidad de abrigar familias de composiciones variadas con criterios mínimos de confort. Una parte de las acciones gubernamentales direccionadas a la población de bajos ingresos debe involucrar, además de la construcción de casas, la recalificación de los inmuebles y la prestación de asistencia técnica. El presente artículo tiene el propósito de proponer un criterio para evaluar la privacidad interna de las viviendas por medio de un indicador de necesidades de ampliaciones, estimado a partir de un número necesario de piezas de apoyo, dormitorios y baños, en base a la edad, sexo y status conyugal de los habitantes. Asimismo, los criterios propuestos califican el indicador en siete niveles de necesidad, que varían entre la ampliación de solamente una pieza, a un nivel más bajo, hasta la necesidad de construcción de baño y por lo menos más cuatro aposentos, a su nivel más avanzado. Se entiende que el indicador propuesto puede ser útil en la concepción de políticas públicas destinadas a reformar y ampliar las residencias. Los resultados indican que el $46 \%$ de las viviendas brasileñas en 2008 demandaban reformas o ampliaciones, pero la calificación de dicha demanda indica que las políticas públicas destinadas a las reformas podrían abordar, por ejemplo, niveles más avanzados de inadecuación que totalizarían, aproximadamente, un 16\% de las viviendas en Brasil. La mayor proporción de viviendas adecuadas se verifica en la Región Sur (67\%) y la peor en la Región Norte, donde sólo un 37\% de ellas son apropiadas.

Palabras clave: Demografía aplicada. Vivienda. Déficit habitacional. Hacinamiento. Cohabitación.

Recebido para publicação em 15/06/2011

Aceito para publicação em 14/11/2011 
